\title{
Myocardial Glutathione Depletion Impairs Recovery of Isolated Blood-perfused Hearts After Global Ischaemia
}

\author{
Steven W. Werns, Joseph C. Fantone, Anthony Ventura and Benedict R. Lucchesi \\ Departments of Pharmacology, Pathology and Internal Medicine (Division of Cardiology), \\ The University of Michigan Medical School, Ann Arbor, Michigan 48109, USA \\ (Received 10 February 1992, accepted in revised form 13 May 1992)
}

\begin{abstract}
S. W. Werns, J. C. Fantone, A. Ventura, B. R. Lucchesi. Myocardial Glutathione Depletion Impairs Recovery of Isolated Blood-Perfused Hearts After Global Ischaemia. Journal of Molecular and Cellular Cardiolog (1992) 24, 1215-1220. This study was performed to determine whether depletion of myocardial glutathione would impair recovery of left ventricular function of blood-perfused, isolated hearts after reversible ischaemic injury. Cats were treated with either vehicle or buthionine sulfoximine (BSO), an inhibitor of gammaglutamylcysteine synthetase, the rate-limiting enzyme in the synthesis of glutathione. The feline isolated hearts were perfused with the blood of normal donor cats before and after $40 \mathrm{~min}$ of global myocardial ischaemia. The myocardial concentration of glutathione of the BSO group, $178 \pm 38 \mathrm{ng} / \mathrm{mg}$ tissue, was significantly less than that of the control group, $292 \pm 38 \mathrm{ng} / \mathrm{mg}$ tissue $(P<0.05)$. The peak left ventricular developed pressure (LVDP) $1 \mathrm{~h}$ after reperfusion, expressed as a fraction of the peak LVDP before ischaemia, was $0.87 \pm 0.10$ for the control group and $0.64 \pm 0.08$ for the BSO group $(P=0.05 \mathrm{vs}$. control $)$. The peak left ventricular $\mathrm{d} P / \mathrm{d} t$ after reperfusion, expressed as a fraction of the peak $\mathrm{d} P / \mathrm{d} t$ before ischacmia, was $1.08 \pm 0.14$ for the control group and $0.78 \pm 0.09$ for the BSO group ( $P=0.05 \mathrm{vs}$. control). The myocardial creatine kinase activity of the BSO group, $1046 \pm 46 \mathrm{U} / \mathrm{g}$ tissue, was not significantly different from that of the control group, $1038 \pm 17 \mathrm{~L} / \mathrm{g}^{\mathrm{sissue}}$ $(P=0.87)$. Thus, depletion of myocardial glutathione resulted in impaired post-ischaemic contractile function that cannot be attributed to a greater extent of irreversible cell injury.
\end{abstract}

KEY Words: Glutathione; Buthionine sulfoximine; Reperfusion injury.

\section{Introduction}

Myocardial stunning refers to the delayed recovery of contractile function after either regional or global myocardial ischaemia which results in reversible myocardial injury [1]. Numerous studies have supported the hypothesis that the pathogenesis of myocardial stunning involves the formation of oxygen metabolites, such as superoxide anion, hydrogen perioxide and hydroxyl radical [1]. Reduced glutathione (GSH) and glutathione peroxidase constitute the major intracellular defenses against damage by hydrogen peroxide and lipid hydroperoxides [2,3]. This study was designed to evaluate the importance of myocardial glutathione by determining the effect of myocardial glutathione depletion on myocardial stunning after global myocardial ischaemia. Depletion of glutathione was achieved by treatment with buthionine sul- foximine (BSO), an inhibitor of gammaglutamylcysteine synthetase, the rate-limiting enzyme in the synthesis of glutathione $[7]$.

\section{Methods \\ Preparation of blood-donor cal}

The blood-perfused, feline isolated heart preparation was developed by Vogel and Lucchesi [5] and has been used to study the effects of a variety of pharmacological interventions, including $\beta$-adrenergic blockade [6], calcium channel blockade [7], and SOD and catalase [8], on myocardial injury due to global ischaemia and reperfusion. Hearts from mongrel cats of either sex were isolated and perfused via the aorta with blood drawn from a blooddonor cat. Blood-donor cats $(3-5 \mathrm{~kg})$ were anesthetized with $0.7 \mathrm{ml} / \mathrm{kg}$ iv of a dial-ureth-

Please address all correspondence to: Benedict R. Lucchesi, Department of Pharmacology, M6322 Medical Science Building 1, Lniversity of Michigan Medical School, Ann Arbor, MI 48109-0626, USA. 
ane solution containing: allobarbital, $100 \mathrm{~g} / \mathrm{l}$; urethane, $400 \mathrm{~g} / \mathrm{l}$; monoethylurea, $400 \mathrm{~g} / 1$. The cats were anticoagulated with $300 \mathrm{U} / \mathrm{kg}$ iv sodium heparin. A femoral vein was isolated, cannulated and connected through a roller pump to a venous reservoir. The reservoir level was adjusted to maintain the diastolic blood pressure of the blood-donor cat above $75 \mathrm{mmHg}$. One femoral artery was isolated, cannulated and connected to a second roller pump for withdrawal of arterial blood. The other femoral artery was cannulated to monitor systemic blood pressure. The trachea was cannulated for positive-pressure ventilation. Tidal volume was adjusted to maintain arterial $\mathrm{pH}, P_{2}$, and $P_{\mathrm{CO}_{2}}$ within normal limits.

\section{Preparation of isolated heart}

Buthionine sulfoximine was obtained from Sigma Chemical, St. Louis, MI. After preparation of the donor cat as described above, the control or BSO-treated cats were anesthetized with $35 \mathrm{mg} / \mathrm{kg}$ iv sodium pentobarbital and anticoagulated with $300 \mathrm{U} / \mathrm{kg}$ iv sodium heparin. The heart was excised quickly and mounted on the perfusion apparatus. Arterial blood, drawn by the roller pump from the blood-donor cat, was maintained at $37^{\circ} \mathrm{C}$ by a heat exchanger and monitored continuously with a thermistor probe. The perfusion pressure was recorded with a pressure transducer connected to a side arm of the aortic cannula, and was maintained at $75 \mathrm{mmHg}$ by manually varying the flow rate of the perfusion pump. The isolated hearts were suspended in a water-jacketed vessel maintained at $37^{\circ} \mathrm{C}$. During ischaemic arrest the hearts were immersed in $0.9 \%$ sodium chloride solution. Otherwise the hearts were kept moist by periodically applying $0.9 \%$ sodium chloride to the surface.

The vena cava and pulmonary veins were ligated and the pulmonary artery was cannulated to collect the coronary venous effluent, which was returned to the jugular vein of the blood-donor cat via the venous reservoir and roller pump. A left ventricular drainage cannula was secured at the apex of the heart with purse string sutures. Blond collected through the drainage cannula $(<1 \mathrm{ml} / \mathrm{min})$ was returned to the venous reservoir. The hearts were paced electrically from the right atrial appendage at a rate of 150 beats $/ \mathrm{min}$. An electrocardiogram was recorded from the isolated heart with one electrode attached to the aortic cannula and another to the apex of the heart.

Left ventricular volume was controlled with a water-filled latex balloon placed in the ventricle through the left atrial appendage. The balloon was connected by a short length of stiff polyethylene tubing to a syringe and a pressure transducer. Left ventricular pressure and its electronically derived first derivative $(\mathrm{d} P / \mathrm{d} t)$ were recorded through this system. Ventricular function curves were inscribed by increasing the volume of the balloon by $0.2 \mathrm{ml}$ increments so that ventricular diastolic pressure varied between 0 and $35 \mathrm{mmHg}$.

After stabilization for $60 \mathrm{~min}$, the left ventricular pressure and $\mathrm{d} P / \mathrm{d} t$ were recorded for left ventricular end-diastolic pressures varying from 0 to $35 \mathrm{mmHg}$ by adjusting the balloon volume. The balloon volume was adjusted to the value that produced a left ventricular diastolic pressure of $15 \mathrm{mmHg}$. The hearts were subjected to zero-flow ischaemia for $40 \mathrm{~min}$, followed by reperfusion. Fifty per cent of the hearts from each group developed ventricular fibrillation after reperfusion and were defibrillated with injections of $100 \mu \mathrm{l}$ of saturated $\mathrm{KCl}$ solution into the perfusion cannula. The perfusate was not allowed to recirculate. After reperfusion for $60 \mathrm{~min}$ the hemodynamic measurements were repeated.

\section{Tissue creatine kinase and glutathione}

Samples of blood were obtained from the pulmonary artery cannula $10 \mathrm{~min}$ after reperfusion to measure oxidized glutathionc as described below. After reperfusion for $60 \mathrm{~min}$ and recording of the post-ischaemic left ventricular function curves, the hearts were perfused with $100 \mathrm{ml}$ of Kreb's buffer to wash out the blood in the vascular space. The hearts were then freeze-clamped with tongs precooled in liquid nitrogen.

\section{Creatine kinase}

Previous studies have shown that the myocardial CK activity of isolated, blood-perfused cat hearts was unchanged after $40 \mathrm{~min}$ of 
ischaemia, suggesting reversible cell injury [5]. The myocardial CK activities were determined using a commercial spectrophotometric assay (Sigma Chemical, St. Louis, MI). Phosphocreatine formed in the CK-catalyzed reaction between ATP and creatine is hydrolyzed to yield inorganic phosphorus, which is quantitated by the Fiske and SubbaRow method. Thus, the myocardium was homogenized in a phosphate-free buffer of $250 \mathrm{~mm}$ sucrose, $1 \mathrm{~mm}$ EDTA, 0.1 mm mercaptoethanol [9]. The $\mathrm{CK}$ artivities of tissue samples was extrapolated from a standard curve of phosphate and $\mathrm{CK}$ standards.

\section{Glutathione}

The myocardial concentration of total glutathione was measured as described by Griffith and Meister [10]. The assay for GSH is an enzymatic recycling assay in which GSH is sequentially oxidized by 5,5-dithiobis (2-nitrobenzoic acid) (DTNB) and reduced by glulathione reductase and NADPH [11]. The rate of 5-thio-2-nitrobenzoic acid formation is monitored at $412 \mathrm{~nm}$, and is proportional to the sum of GSH and 2X GSSG. The glutathione concentration of the tissue sample was extrapolated from a standard curve.

The concentration of oxidized glutathione in pulmonary artery plasma was measured as described by Anderson [11]. Fifty microliters of $500 \mathrm{~mm}$ EDT $A$ was added to $5 \mathrm{ml}$ of blood. Aliquots of $400 \mu \mathrm{l}$ were centrifuged at $10000 \mathrm{~g}$ for 90 seconds. One hundred $\mu \mathrm{l}$ of $10 \%$ sulfosalicyclic acid was added to $200 \mu \mathrm{l}$ aliquots of plasma and centrifuged at $10000 \mathrm{~g}$ for $5 \mathrm{~min}$. The supernatants were stored overnight at $4^{\circ} \mathrm{C}$. On the following day $4 \mu \mathrm{l}$ of 2vinylpyridine were added to $200 \mu \mathrm{l}$ aliquots of supernatant. The samples were mixed with i) $\mu \mathrm{l}$ of triethanolamine and incubated for 60 min at room temperature. The concentration of oxidized glutathione was extrapolated from a standard curve.

\section{Data analysis}

All data are expressed as means \pm S.E.M. Differences were considered significant for $P<0.05$. An unpaired $t$ test was used to compare the control and BSO groups.

\section{Results}

The first objective was to identify a schedule of treatment with buthionine sulfoximine (BSO) that significantly reduces the concentration of glutathione in the cat heart. 'The' myocardial concentration of glutathione was $998+79 \mathrm{ng} / \mathrm{mg}$ tissue $(n=2)$ in non-ischaemic cat hearts, a value similar to that reported for the mouse heart [10]. Four hours after the injection of $\mathrm{BSO} 1.6 \mathrm{~g} / \mathrm{kg}$ ip, the myocardial concentration of glutathione was $790 \mathrm{ng} / \mathrm{mg}$ $(n=2)$. The concentration of glutathione wats $617 \mathrm{ng} / \mathrm{mg}(n=1) 18 \mathrm{~h}$ after BSO $1.6 \mathrm{~g} / \mathrm{kg} \mathrm{ip}$. After treatment with BSO $1.6 \mathrm{~g} / \mathrm{kg}$ ip for 2 days, the myocardial concentration of glutathione was $272 \mathrm{ng} / \mathrm{mg} \quad(n=2)$. Therefore, the latter schedule of administration wass selected for subsequent experiments.

Experiments were performed to examine the correlation between the post-ischaemic recovery of left ventricular function and the myocardial concentration of glutathione. Cats were assigned randomly to treatment with either vehicle $(n=6)$ or $\mathrm{BSO}(n=6) 1.6 \mathrm{~g} / \mathrm{kg}$ ip 42 and $18 \mathrm{~h}$ before the experiments. The peak left ventricular developed pressure LVDP? for the control group was $142 \pm 4$ before ischaemia and $121 \pm 12$ after reperfusion $(P=0.11$; see Fig. 1). The peak LVDP for the BSO group was $165 \pm 14$ before ischaemia and $106 \pm 16$ after reperfusion $P=0.005$. The peak LVDP after reperfusion, expressed as a fraction of the peak LVDP before ischaemia. was $0.87 \pm 0.10$ for the control group and $0.64 \pm 0.08$ for the BSO group $(P=0.05 \mathrm{zs}$. control). Similarly, the peak left ventricular $\mathrm{d} P / \mathrm{d} l$ after reperfusion, expressed as a fraction of the peak $\mathrm{d} P / \mathrm{d} l$ before ischaemia, was $1.08 \pm 0.14$ for the control group and $0.78 \pm 0.09$ for the BSO group $(P=0.05$ is. control; see Figure 1,

After reperfusion for $10 \mathrm{~min}$, the concentration of oxidized glutathione in the pulmonary artery plasma was $6.3 \pm 0.2 \mu \mathrm{m}$ for the controls $n=3$ i compared to $3.3 \pm 0.4 \mu \mathrm{m}$ for the BSO group $n=3 ; P<0.01$ is. controls: The myocardial concentration of glutathione was $292 \pm 38 \mathrm{ng} / \mathrm{mg}$ tissue for the control group $(n=6)$, compared to $998 \pm 79 \mathrm{ng} / \mathrm{mg}$ for the non-ischaemic hearts $\mid n=2$ !. Thus, ischaemia and reperfusion resulted in a substantial decline in the myocardial concentra- 

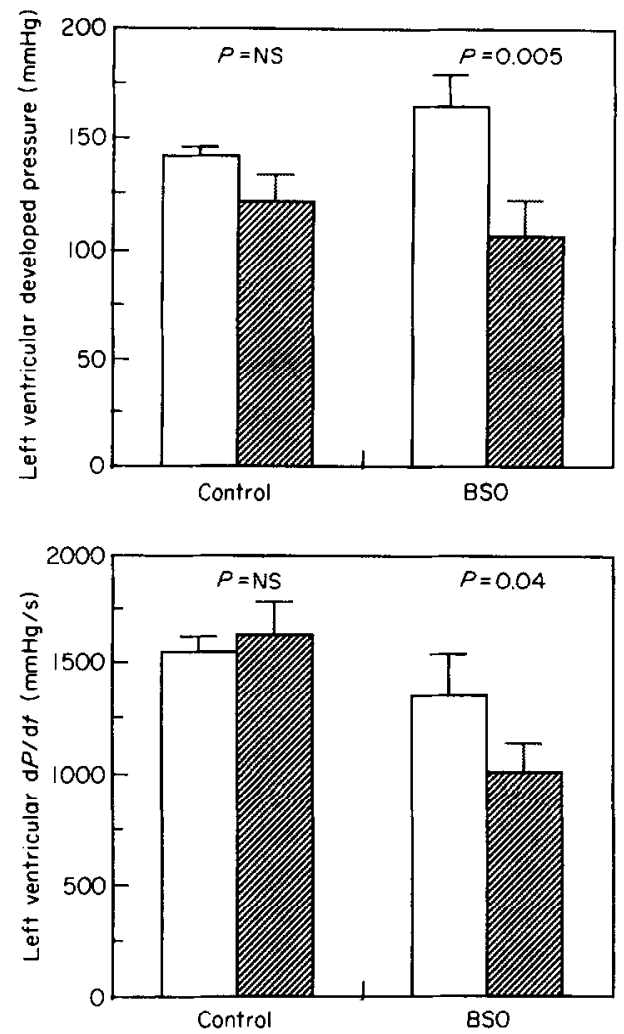

FIGURE 1. Left ventricular developed pressure and $\mathrm{d} P / \mathrm{d} t$ before ischaemia and $\mathrm{I} \mathrm{h}$ after reperfusion of the control group $(n=6)$ and BSO group $(n=6)$. $\square=$ Preischaemia, $\mathbb{Z}=$ post-reperfusion.

tion of glutathione. The myocardial concentration of glutathione of the BSO group, $178 \pm 38 \mathrm{ng} / \mathrm{mg}(n=5)$, was significantly less than that of the control group $(P<0.05 v s$. control). There was a significant correlation between the myocardial concentration of glutathione and the peak LVDP after reperfusion expressed as a percentage of the peak LVDP before ischaemia ( $\mathrm{R}=0.64, P=0.03$ ).

The myocardial creatine kinase activity (CK) of the BSO group, $1046 \pm 46 \mathrm{U} / \mathrm{g}$ tissue $(n=5)$, was not significantly different from that of the control group, $1038 \pm 17 \mathrm{U} / \mathrm{g}$ tissue $(n=6 ; P=0.87)$. Therefore, the depletion of glutathione appears to have caused an impairment of post-ischaemic contractile function that cannot be attributed to a greater extent of irreversible cell injury.

\section{Discussion}

The results demonstrate that (1) there is a significant reduction of the total glutathione concentration of cat hearts subjected to global ischaemia for $40 \mathrm{~min}$ followed by reperfusion for $60 \mathrm{~min},(2)$ the myocardial concentration of glutathione is significantly reduced in cats treated with BSO and (3) inhibition of glutathione synthesis by treatment with BSO results in significantly less recovery of left ventricular developed pressure and $\mathrm{d} P / \mathrm{d} t$ after global ischaemia and reperfusion. The results support the hypothesis that myocardial glutathione protects the heart against injury caused by ischaemia and reperfusion.

Although myocardial glutathione depletion has been studied previously, a unique aspect of this study is the glutathione-depleted hearts were perfused with blood from a normal donor animal. Previous studies have examined either isolated crystalloid-perfused hearts [12], or the in-situ hearts of animals subjected to systemic depletion of glutathione [13]. Normal erythrocytes contain catalase, glutathione peroxidase, and glutathione, and may serve as a major defense against the effects of hydrogen peroxide [14-17]. Toth et al. [14] reported that addition of human erythrocytes decreased damage to cultured endothelial cells and isolated rat lungs which were exposed to hydrogen peroxide. Winterbourn et al. [15] demonstrated that human erythrocytes scavenge extracellular hydrogen peroxide, inhibiting the formation of hypochlorous acid and hydroxyl radicals. Several studies have concluded that the protection from hydrogen peroxide by erythrocytes is mediated primarily by catalase $[15,17]$. Other investigators, however, have provided evidence that both erythrocyte catalase and glutathione can de. crease reperfusion injury [16]. Brown et al. [16] added human crythrocytes to the perfusate during reperfusion of isolated rat hearts after global ischaemia. Intact erythrocytes decreased the myocardial concentration of hydrogen peroxide and improved the recovery of ventricular function. The beneficial effect of the erythrocytes was reduced by treatment of the erythrocytes with either aminotriazole, which inactivates catalase, or N-ethyolmaleimide, which both alkylates GSH and inhibits regeneration of GSH by GSH reductase [18]. 
The current study is the first to demonstrate the importance of myocardial glutathione in the presence of intact erythrocytes.

Blaustein et al. [12] treated rats with diethylmaleate (DEM), which reduced the cardiac glutathione concentration to $35 \%$ of control hearts. The rat hearts were subjected to crystalloid perfusion and global ischaemia for $20 \mathrm{~min}$. The glutathione-depleted hearts exhibited impaired recovery of systolic function after reperfusion. DEM depletes glutathione via the formation of a thioether adduct, but it also inhibits protein synthesis, which might influence the results of the latter study [19]. BSO, however, does not inhibit protein synthesis, and reduces the concentration of glutathione by inhibiting gamma-glutamylcysteine synthetase, the rate-limiting enzyme in the synthesis of glutathione $[10,19,20]$. Only one previous study has employed BSO to inhibit myocardial glutathione synthesis [13]. The experimental preparation employed in the latter study, however, consisted of coronary artery occlusion in vivo, which resulted in myocardial infarction, and in addition to the heart, rirculating erythrocytes, leukocytes and plasma were subjected to glutathione depletion. The experimental preparation utilized in the current study featurcd untreatcd erythrocytes and leukocytes, and normal plasma, and the duration of ischaemia produces reversible myocardial injury rather than myocardial infarction. Previous work from this laboratory demonstrated a pattern of hemodynamic and biochemical changes consistent with reversible injury, i.e. myocardial stunning, after isolated, blood-perfused cat hearts were subjected to $40 \mathrm{~min}$ of ischaemia: impaired recovery of systolic function without the accumulation of calcium and loss of creatine kinase exhibited by infarcted tissue [4].

Additional studies have attempted to determine whether an increased cellular concentration of GSH would ameliorate post-ischaemic myocardial injury. Enrichment of the cardiac perfusate with GSH was reported to improve the recovery of left ventricular function of isolated rat hearts subjected to global ischaemia and reperfusion $[12,21]$. The improvement in function, however, is probably not due to an increased intracellular pool of GSH. Glutathione itself is not effectively transported into cells [22], suggesting that the GSH in the cardiac perfusate may have exerted unrecognized effects. Employing a model of hypoxic injury to renal tubules, Weinberg $e t$ al. [23] concluded that the cytoprotective effect of exogenous GSH may be due to a protective effect of the glycine derived from GSH. The cxogenous GSH added to isolated renal proximal tubules was degraded rapidly to its component amino acids, glutamate, cysteine and glycine. Treatment with cysteine, but not glycine, increased the intracellular concentration of GSH, but only glycine attenuated hypoxic injury to the renal tubules.

$\mathrm{N}$-acetylcysteine has been shown to increase intracellular concentrations of $\mathrm{GSH}$ by increasing the availability of cysteine [22]. Administration of $\mathrm{N}$-acetylcysteine to dogs did not limit the extent of myocardial necrosis after coronary artery occlusion, although the post-ischaemic recovery of left ventricular function was improved [24]. Compared to control hearts, isolated rabbit hearts treated continuously with $\mathrm{N}$-acetylcysteine before, during and after global ischaemia exhibited less efflux of creatine kinase and better left ventricular function after reperfusion [2.5]. The interpretation of the latter study is confounded by the fact that pretreatment with $\mathrm{N}$-acetylcysteine exerted only a modest effect on the post-ischaemic myocardial concentration of $\mathrm{GSH} \quad 8.3 \mathrm{nmol} / \mathrm{mg}$ protein $u$. $6.5 \mathrm{nmol} / \mathrm{mg}$ protein in controls), and the addition of $\mathrm{N}$-acetylcysteine to the perfusate throughout ischaemia and reperfusion would have exerted an antioxidant action.

Ferrari et al. [26] measured the release of GSH and oxidized glutathione from human hearts subjected to global myocardial ischaemia during coronary artery bypass grafting, and found indirect cvidence of "oxidative stress" during reperfusion. Thus, both clinical and experimental studies suggest that myocardial glutathione stores may be an important component of the heart's susceptibility to reperfusion injury.

\section{Acknowledgements}

The authors would like to thank ( $a$ aren M Stalburg, Beatrice Manzor, Sean Pfeffer, and GuIm Kwon for their technical assistance. Supported by grant HL-19782-14 from the National Institutes of Health, Heart, Lung and Blood Institute. 


\section{References}

I Bolli, R. Mechanism of myocardial "stunning". Circulation 82, 723-738 (1990).

2 Tribble, D. L., Kennedy, F. G., Jones, D. P. Contrasting features of peroxide metabolism in the heart and liver. In: Oxygen Radicals in the Pathuphysiology of Heart Disease, edited by P. K. Singal. Boston, MA: Kluwer Academic Publishers, pp. 25-40 (1988).

3 Simmons, T. W., Jamall, I. S. Relative importance of intracellular glutathione peroxidase and catalase in vivo for prevention of peroxidation to the heart. Cardiovasc Res 23, 774-779 (1989).

4 Griffith, O. W., Meister, A. Potent and specific inhibition of glutathione synthesis by buthionine sulfoximine (s- $n$ butyl homocysteine sulfoximine). J Biol Chem 254, 7558-7560 (1979).

5 Vocel, W. M., Lucchesi, B. R. An isolated, blood-perfused, feline heart preparation for evaluating pharmacological interventions during myocardial ischemia. J Pharmacol Meth 4, 291-303 (1980).

6 Bush, L. R., Haack, D. W., Shlafer, M., Lucchesi, B. R. Protective effects of $\beta$-adrenergic blockade in isolated ischemic hearts. Eur J Pharmacol 67, 209-217 (1980).

7 Bush, L. R., Li, Y.-P., Shlafer, M., Jolly, S. R., Lucchesi, B. R. Protective effects of diltiazem during myocardial ischemia in isolated cat hearts. J Pharmacol Exp Ther 218, 653-66l (1981).

8 Shlafer, M., Kane, P. F., Wiggins, V. Y., Kirsh, M. M. Possible role for cytotoxic oxygen metabolites in the pathogenesis of cardiac ischemic injury. Circulation 66 (suppl. I); I-85-I-92 (1982).

9 KJekshus, J. K., Sobel, B. E. Depressed myocardial creatine phosphokinase activity following experimental myocardial infarction in rabbit. Circ Res XXVII, 403-414 (1970).

10 Griffith, O. W., Meister, A. Glutathione: Interorgan translocation, turnover, and metabolism. Proc Natl Acad Sci 76, 5606-5610 (1979).

11 Anderson, M. E. Determination of glutathione and glutathione disulfide in biological samples. Meth Enzymol 113, $548-555(1985)$.

12 Blaustein, A., Deneke, S. M., Stolz, R. I., Buxter, D., Henley, N., Fanburg, B. L. Myocardial glutathione depletion impairs recovery after short periods of ischemia. Circulation 80, 1449-1457 (1989).

13 Singh, A., Lee, K. J., Lee, C. Y., Goldfarb, R. D., Tsan, M.-F. Relation between myocardial glutathione content and extent of ischemia-reperfusion injury. Circulation 80, 1795-1804 (1989).

14 Toth, K. M., Clifford, D. P., Berger, E. M., White, C. W., Repine, J. E. Intact human erythrocytes prevent hydrogen peroxide-mediated damage to isolated perfused rat lungs and cultured bovine pulmonary artery endothelial cells. J Clin Invest 74, 292-295 (1984).

15 Winterbourn, C. C., Stern, A. Human red cells scavenge extracellular hydrogen peroxide and inhibit formation of hypochlorous acid and hydroxyl radical. J Clin Invest 80, 1486-1491 (1987).

16 Brown, J. M., Grosso, M. A., Terada, L. S., Beehler, C. J., Toth, K. M., Whitman, G. J., Harken, A. H., Repine, J. E. Erythrocytes decrease myocardial hydrogen peroxide levels and reperfusion injury. Am J Physiol 256. H584-H588 (1989).

17 Agar, N. S., Sadrzadeh, S. M. H., Hallaway, P. E., Eaton, J. W. Erythrocyte catalase. A somatic oxidant defense? J Clin Invest 77, 319-321 (1986).

18 Meister, A., Anderson, M. E. Glutathione. Ann Rev Biochem 52, 711-760 (1983).

19 Costa, L. G., Murphy, S. D. Effect of diethylmaleate and other glutathione depletors on protein synthesis. Biochem Pharmacol 35, 3383-3388 (1986).

20 Drew, R., Mineks, J. O. The effects of buthionine sulphoximine (BSO) on glutathione deplecion and xenobiutic biotransformation. Biochem Pharmacol 33, 2989-2994 (1984).

21 Menasche, P., Grousset, C., Gauduel, Y., Piwnica, A. A comparative study of free radical scavengers in cardioplegic solutions. Improved protection with pernxidase. J Thorac Cardinvase Surg 92, 264-271 (1986).

22 Meister, A. New aspects of glutathione biochemistry and transport: selective alteration of glutathione metabolism. Fed Proc 43, 3031-3042 (1984).

23 Weinberg, J. M., Davis, J. A., Abarzua, M., Rajan, T. Gytoprotective effects of glycine and glutathione against hypoxic injury to renal tubules. J Clin Invest 80, 1446-1454 (1987).

24 Forman, M. B., Puett, D. W., Cates, C. U., McCroskey, D. E., Begkman, J. K., Greene, H. L., Virmani, R. Glutathione redox pathway and reperfusion injury: effect of $\mathrm{N}$-acetylcysteine on infarct size and ventricular function. Circulation 78, 202-213 (1988).

25 Ceconi, C., Curello, S., Cargnoni, A., Ferrari, R., Albertini, A., Visioli, O. The role of glutathione status in the protection against ischaemic and reperfusion damage: effects of $\mathrm{N}$-acetyl cysteine. $\mathrm{J}$ Mol Cell Cardiol 20, 5-13 (1988).

26 Ferrari, R., Alfieri, O., Curello, S., Ceconi, C., Gargnoni, A., Marzollo, P., Pardini, A., Caradonna, E., Visioli, O. Occurrence of oxidative stress during reperfusion of the human heart. Circulation 81, 201-211 (1990). 